\title{
Sub-atomic resolution X-ray diffraction of the SH3 domain from the post-synaptic density protein Shank3
}

\author{
Srinivas Kumar Ponna ${ }^{a}$, Matti Myllykoski ${ }^{a}$, Tobias M. Boeckers ${ }^{b}$ and Petri Kursula ${ }^{a c *}$ \\ aFaculty of Biochemistry and Molecular Medicine and Biocenter Oulu, University of Oulu, PO Box 5400, Oulu, 90014, \\ Finland \\ ' Institute for Anatomy and Cell Biology, University of Ulm, Albert Einstein Allee 11, Ulm, 89081, Germany \\ 'Department of Biomedicine, University of Bergen, Jonas Lies vei 91, Bergen, 5009, Norway \\ Correspondence email: petri.kursula@uib.no
}

\begin{abstract}
The post-synaptic density multidomain scaffolding proteins of the Shank family are structurally poorly characterised. The Shank family consists of three members, and domain-specific interactions of Shank are involved in forming a network of proteins at the post-synaptic region for intracellular signalling and cellular scaffolding. While X-ray crystallography has provided some information on individual Shank domains, the structural basis of Shank interactions is still largely unknown. In this study, the production and crystallisation of the previously uncharacterised Shank3 SH3 domain is presented. The highly twinned crystals diffracted synchrotron X-rays to a resolution higher than $0.9 \AA$, and these crystals will eventually have the potential to provide an ultrahigh-resolution view into the Shank family SH3 domains and their interactions.
\end{abstract}




\section{Introduction}

The Shank proteins were first identified by different research groups in 1999, as novel proteins expressed in human and rodent brains, and being concentrated at the post-synaptic density (Boeckers et al., 1999; Naisbitt et al., 1999; Tu et al., 1999; Zitzer et al., 1999). Shank family proteins (Shank1, Shank2, and Shank3) are post-synaptic density (PSD) scaffolding proteins. They are multidomain proteins, which coordinate protein-protein interactions at the PSD, and they can interact directly or indirectly with post-synaptic receptors, such as NMDA type and metabotropic glutamate receptors, as well as with the actin-based cytoskeleton (Boeckers et al., 2002). Full-length Shank proteins consist of an $\mathrm{N}$-terminal region, multiple ankyrin repeats, a Src homology 3 domain (SH3), a PDZ domain, a long proline-rich region, and a sterile alpha motif (SAM). All these domains are believed to have specific interactions with partner proteins for intracellular signalling. The binding partners for the Shank3 SH3 (Shank3-SH3) domain are currently unknown for all the Shank proteins; a possible interaction between Shank3-SH3 and phospholipase $\mathrm{C} \beta 1 \mathrm{~b}$, which carries proline-rich segments in its $C$ terminus, was suggested (Grubb et al., 2011), but such a direct interaction has not been confirmed at the molecular level. Another suggested SH3 interaction was reported for GRIP1 (Sheng \& Kim, 2000), but also that interaction has remained unproven at the molecular level.

In the brain, Shank proteins are mainly expressed in the cortex, hippocampus, and amygdala and moderately in thalamus and substantia nigra; neuron-specific expression is seen in the cerebellum (Boeckers et al., 1999; Zitzer et al., 1999). Shank3 is one of the most heavily studied proteins involved in neurological disorders, and mutations in Shank are implicated in many neurological diseases. For example, a de novo mutation in Shank3 was reported to cause schizophrenia (Grabrucker et al., 2014). Mutations in the Shank3 gene have been reported to cause autism spectrum disorders (ASD) (Durand et al., 2006). On the other hand, overexpression of Shank3 causes hyperkinetic neuropsycopathy disorders (Han et al., 2013). All these disorders are likely to be related to disturbances in the interactions at the post-synaptic density.

Understanding the nature of a protein at the molecular level will give a detailed insight into disorders caused by mutations. Since Shank3 has domain-specific interactions at the post synapse, understanding the structural and functional aspects of different domains will give detailed information about the behaviour of the domain and its interactions with partner proteins. The SH3 domains of the three different Shank proteins are very similar; on the other hand, their sequence is poorly conserved compared to other SH3 domains. Hence, a structural study can be expected to shed light on Shank-specific features and functions of SH3 domains. In this paper, we present protein production, crystallisation conditions, and diffraction data collection for the Shank3 SH3 domain. The crystals diffracting to sub-atomic resolution turned out to be near-perfectly twinned.

\section{Materials \& Methods}

The region encoding the SH3 domain of rat Shank3 (residues 470-528; Table 1) was amplified by PCR, using rat Shank3 cDNA as template, and subcloned into the pDONR221 vector. The Gateway system, based on homologous recombination, was used to further transfer the insert into pTH27 (Hammarström et al., 2006).

Recombinant Shank3-SH3 was produced as a His-tagged version in Escherichia coli Rosetta(DE3) cells. The protein was expressed in 1 liter of autoinduction medium (Studier, 2005) at $310 \mathrm{~K}$ overnight. Cells were harvested and resuspended in $50 \mathrm{ml}$ of lysis buffer ( $50 \mathrm{mM}$ phosphate buffer, $300 \mathrm{mM} \mathrm{NaCl}, 10 \mathrm{mM}$ imidazole, $\mathrm{pH} 7.0$ ) and lysed with 10-15 cycles of sonication for $10 \mathrm{~s}$ each using a Branson sonicator and a 1/2" tapped horn. Cell debris was removed by centrifugation at $15000 \mathrm{rpm}(27000 \mathrm{~g})$ at $277 \mathrm{~K}$ for $40 \mathrm{~min}$. The supernatant, containing the soluble Shank3-SH3 protein, was loaded onto a gravity flow Ni-NTA column. Then, the matrix was washed 3 times with $10 \mathrm{ml}$ of lysis buffer, and the bound protein was eluted with elution buffer $(50 \mathrm{mM}$ phosphate buffer, $300 \mathrm{mM} \mathrm{NaCl}, 500 \mathrm{mM}$ imidazole, $\mathrm{pH}$ 7.0).

The eluted protein was dialysed overnight against dialysis buffer (50 mM HEPES, 150mM NaCl, 1mM DTT, pH 7.0), and simultaneously, the affinity tag was cleaved using TEV protease (van den Berg et al., 2006). The cleaved protein was then passed again through a Ni-NTA column to remove TEV protease, the His tag, and uncut protein. The protein was concentrated using $3 \mathrm{~K}$ Amicon ultra centrifugal filters, and gel filtration was used as the final purification step prior to crystallisation screening. For gel filtration the same buffer as the dialysis buffer, but without DTT, was used. Shank-SH3 
was run through a Superdex S75 16/60 column (GE Healthcare), and pure protein fractions were collected and concentrated to $20 \mathrm{mg} / \mathrm{ml}$ and used for crystallisation screening. Total yield of the protein was $6 \mathrm{mg}(20 \mathrm{mg} / \mathrm{ml}$ in 300 $\mu l)$ from 1 liter of bacterial culture.

Table 1. Macromolecule production information for Shank3-SH3. In the protein sequence, the Histag is underlined, and the TEV cleavage site is in bold. The Shank3-SH3 domain has one extra Ser residue at its $\mathrm{N}$ terminus after cleavage.

\begin{tabular}{|c|c|}
\hline source organism & rat \\
\hline DNA source & rat Shank3 cDNA \\
\hline Forward primer & GCTCTGAGAATCTITATITTCAG AGTGTCCCCGGCCG \\
\hline Reverse primer & AGAAAGCTGGGTCTA CTGCACTTCСТCCA \\
\hline Cloning vector & pDONR221 \\
\hline Expression vector & pTH27 \\
\hline Expression host & Escherichia coli Rosetta(DE3) \\
\hline $\begin{array}{c}\text { Complete amino acid sequence of the construct } \\
\text { produced }\end{array}$ & $\begin{array}{c}\text { MGPHHНHНHLESTSLYKKAGSENLYFQ/SV P G R K } \\
\text { F I A V K A H P Q G E G I P L H R E A V K V } \\
\text { LS I G E G G F E G TVKGRTG W P P D C } \\
\text { VEEVQ }\end{array}$ \\
\hline
\end{tabular}

For crystallisation, Shank3-SH3 was concentrated to $20 \mathrm{mg} / \mathrm{ml}$, and crystal screening was carried out in 96-well format using vapour diffusion in sitting drops. The optimised crystallisation conditions are given in Table 2.

Table 2. Crystallisation of Shank3-SH3.

\begin{tabular}{c|c} 
Plate type & TTP 3-drop 96-well plate \\
\hline Temperature $(\mathrm{K})$ & 293 \\
\hline Protein concentration & $20 \mathrm{mg} / \mathrm{ml}$ \\
\hline Buffer composition of protein solution & $50 \mathrm{mM} \mathrm{HEPES}(\mathrm{pH} 7.0), 150 \mathrm{mM} \mathrm{NaCl}$ \\
\hline Composition of reservoir solution & $0.1 \mathrm{M}$ bis-tris $(\mathrm{pH} 6.5), 32.5 \%$ PEG3350 \\
\hline Volume and ratio of drop & $450 \mathrm{nl}$, drop ratio $2: 1$ (protein:buffer) \\
\hline Volume of reservoir & $50 \mu \mathrm{l}$
\end{tabular}

Prior to X-ray diffraction data collection, the crystals were cryo-protected (0.1 M bis-tris pH 6.5, 32.5\% PEG3350, 20\% PEG400) and rapidly cooled in liquid nitrogen. Data from several crystals of Shank3-SH3 were collected on beamline ID23-1 at ESRF, Grenoble, France. The data were processed with XDS (Kabsch, 1988, 2010). Data intensity distributions, as seen for example using phenix.xtriage (Zwart et al., 2005), indicated all the crystals were nearly perfectly twinned, with the likely true space group being $P 2_{1}$ - with a fortuitous $\beta$ angle of $90.05^{\circ}$. The estimated twin fractions for the operator $\mathrm{h},-\mathrm{k},-\mathrm{I}$ ranged between $36-46 \%$ for the different crystals. On the beamline setting, not all high-resolution data available for the best crystals could be collected due to geometric restraints. Data processing statistics for the best crystal that was tested, diffracting to the highest resolution and having the lowest estimated twin fraction, are shown in Table 3. 
Table 3. Data collection and processing. Values for the outer shell are given in parentheses.

\begin{tabular}{|c|c|}
\hline Diffraction source & ESRF ID23-1 \\
\hline Wavelength $(\AA)$ & 0.977 \\
\hline Temperature $(\mathrm{K})$ & 100 \\
\hline Detector & Pilatus 6M \\
\hline Crystal-detector distance (mm) & 121.56 \\
\hline Rotation range per image $\left(^{\circ}\right)$ & 0.15 \\
\hline Total rotation range $\left(^{\circ}\right)$ & 210 \\
\hline Exposure time per image (s) & 0.037 \\
\hline Space group & $\mathrm{P} 2{ }_{1}$ \\
\hline$a, b, c(\AA)$ & $29.74,52.91,31.66$ \\
\hline $\mathrm{a}, \beta, \mathrm{y}\left({ }^{\circ}\right)$ & $90.00,90.05,90.00$ \\
\hline twinning operator (estimated twin fraction) & $h,-k,-l(36 \%)$ \\
\hline Resolution range $(\AA)$ & $50-0.87(0.89-0.87)$ \\
\hline Total No. of reflections & $229188(1375)$ \\
\hline No. of unique reflections & $64681(698)$ \\
\hline Completeness (\%) & $81.0(11.8))^{\#}$ \\
\hline Redundancy & $3.5(2.0)$ \\
\hline$\langle I / \sigma(I)\rangle$ & $20.9(2.1)$ \\
\hline Rmeas & $0.043(0.524)$ \\
\hline Overall $B$ factor from Wilson plot $\left(\AA^{2}\right)$ & 9.2 \\
\hline $\mathrm{CC}_{1 / 2}(\%)$ & $99.8(75.7)$ \\
\hline
\end{tabular}

\# The low completeness at high resolution results from geometrical issues during data collection. For example, between 1.01-0.97 $\AA$, the data are $90.0 \%$ complete, with $\langle 1 / \sigma(I)\rangle=10.1$ and $R_{\text {meas }}=0.122$. 


\section{Results}

In order to obtain a better understanding at the structural level on the Shank family SH3 domains, we produced and crystallised the SH3 domain of rat Shank3. No specific binding partners have yet been confirmed at the molecular level for any of the Shank SH3 domains, despite extensive literature on the Shank proteins and their interactions. The amino acid sequence of the Shank3 SH3 domain is identical between mouse, rat, and humans, and SH3 domains from different Shank proteins are highly similar. Hence, it is likely that the SH3 domains of different Shank family members share similar properties.

The Shank3 SH3 domain could be produced recombinantly at high yields and purity (Fig. 1), and crystals of Shank3-SH3 were readily obtained using standard vapour diffusion methods (Fig. 2).

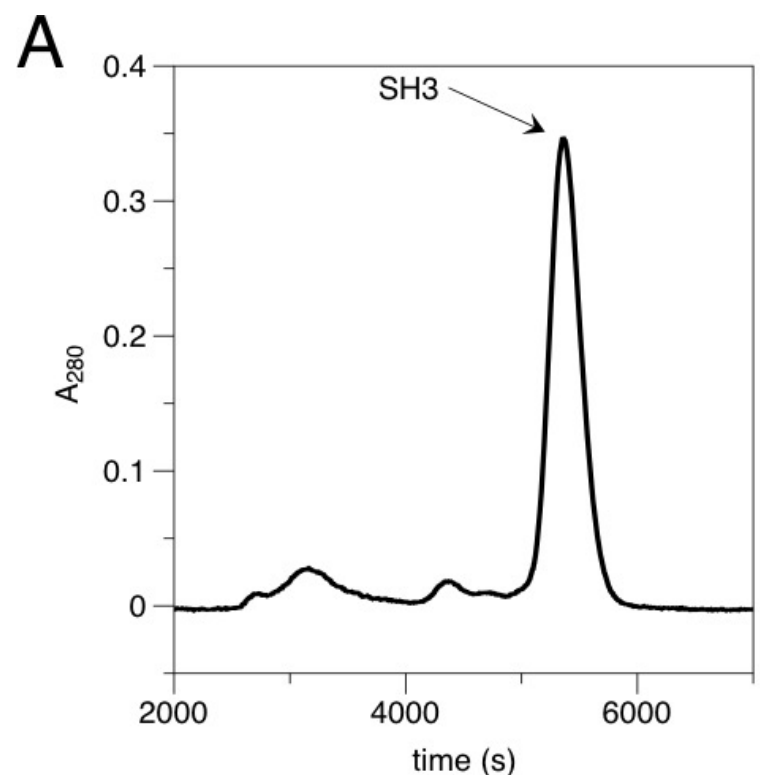

B

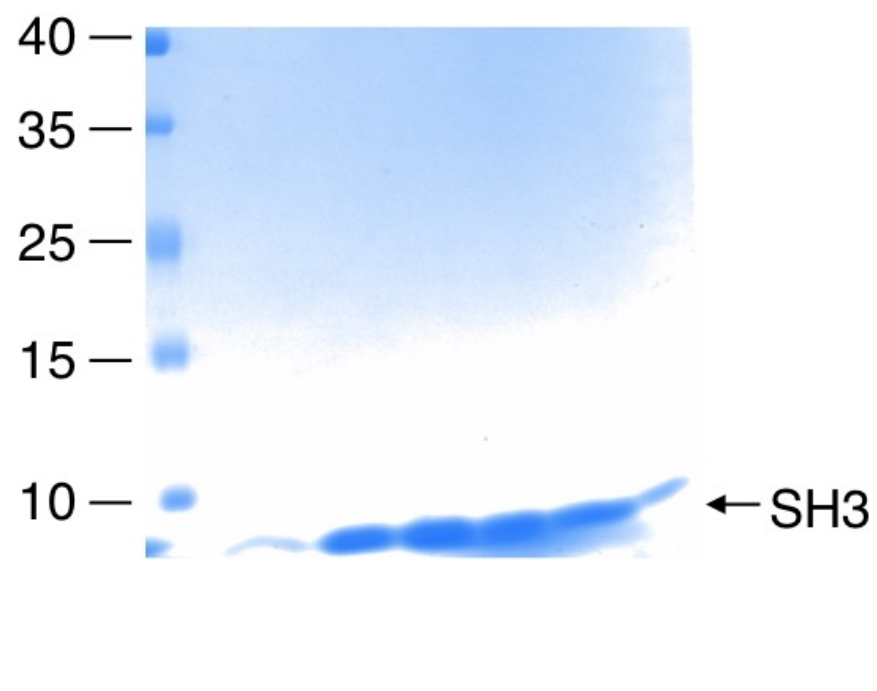

Figure 1. Purification of Shank3-SH3. A. Gel filtration of TEV-cleaved Shank3-SH3. The main peak corresponding to monomeric cleaved protein was collected. B. SDS-PAGE analysis of the gel filtration peak fractions. The position of the SH3 domain is indicated in both panels.

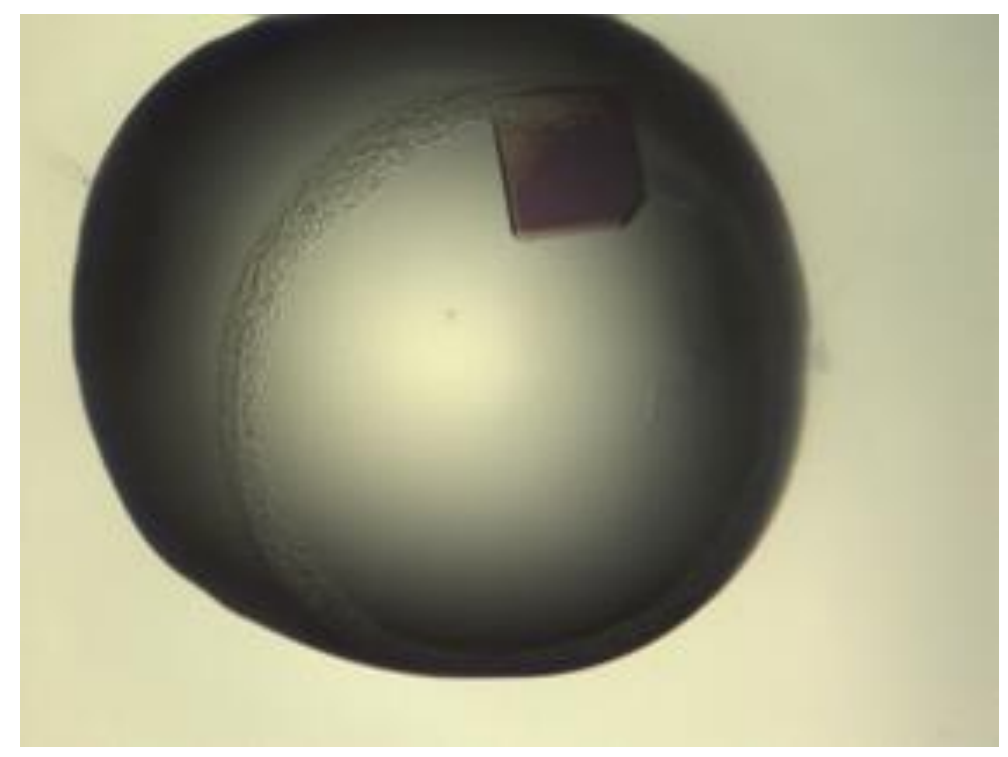

Figure 2. A typical single crystal of Shank3-SH3. The dimensions of the crystal were approx. $450 \times 430 \times 50 \mu \mathrm{m}^{3}$. 
The crystal used for the dataset described here was grown in $0.1 \mathrm{M}$ bis-tris, $32.5 \%$ PEG3350. Diffraction could be observed to a resolution of at least $0.87 \AA$ (Fig. 3).

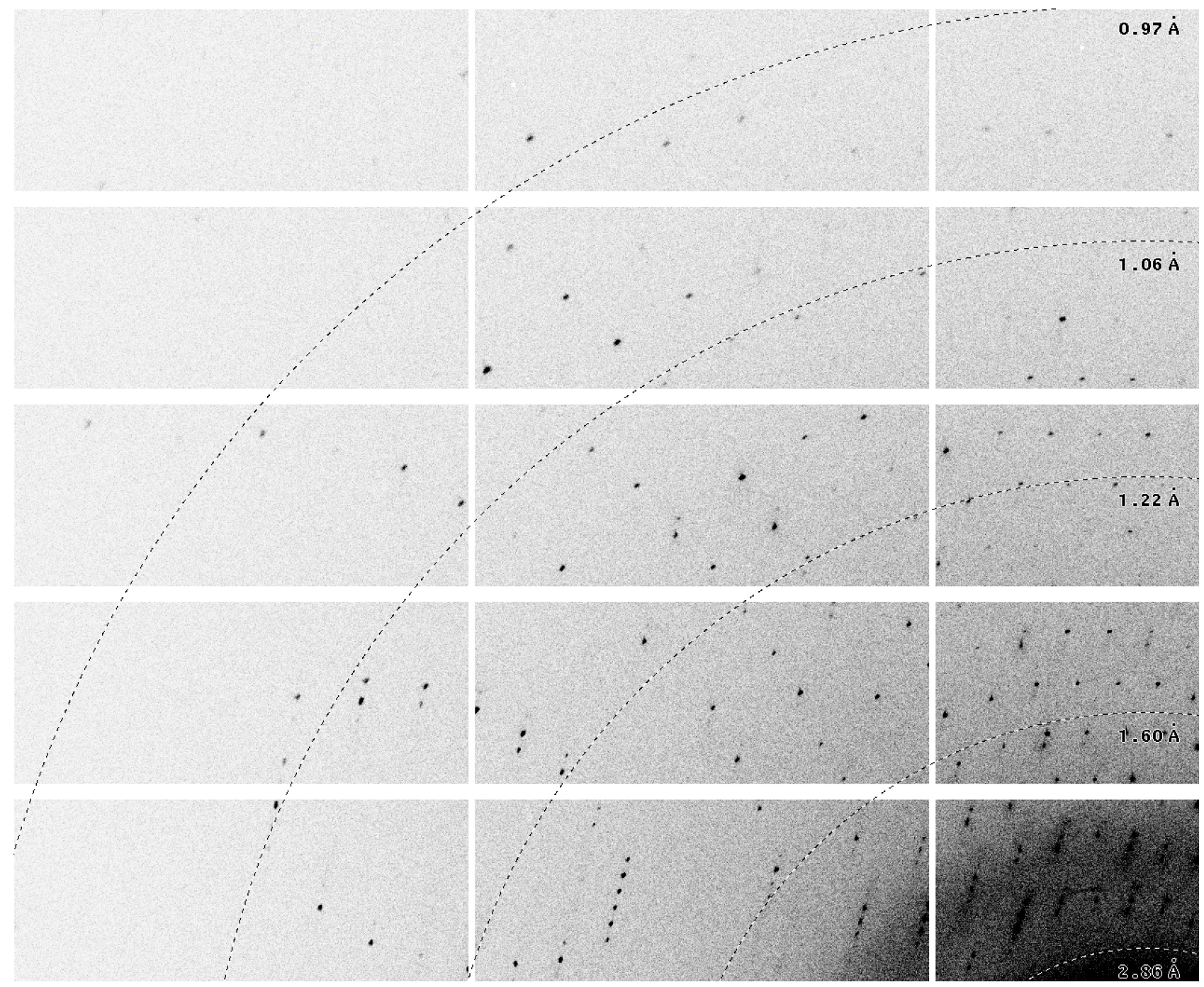

Figure 3. One corner of a diffraction image from the Shank3-SH3 domain crystal, collected on the ESRF beamline ID23-1. The resolution at the detector edge is $0.98 \AA$ and in the corner (top left) $0.87 \AA$.

Initially, an orthorhombic lattice was selected by automatic processing routines at the beamline, but careful investigation of the intensity distributions indicated a high level of twinning with the operator $h,-k,-l$, and hence, all data were reprocessed in a monoclinic setting; systematic absences suggested space group P $2_{1}$. The lowest estimated twinning fraction observed between different crystals was $36 \%$. Thus, the crystals are not necessarily perfectly twinned, which will increase the chances of successful structure solution and refinement in the future.

The processing statistics (Table 3 ) indicate that the full diffraction capacity of the crystal could not be even nearly exploited during the data collection. It is expected that, using an optimised synchrotron beamline setting, we can collect even higher-resolution, complete data for Shank3-SH3 in the near future. This will eventually allow to pinpoint fine details of protein structure using the Shank3-SH3 domain as a tool. The more crucial step before this, however, will be the actual structure solution.

SH3 domains are small proteins containing $\beta$ strands and flexible loops, and their structures are often difficult to solve by molecular replacement. The closest homologues to Shank3-SH3 in the PDB present sequence identities of $\approx 25 \%$ to Shank3, and presumably, experimental phasing will have to be employed to solve the structure. Such low sequence homology for a small domain of $<60$ residues dictates that molecular replacement is unlikely to work. Initial molecular replacement trials, using various SH3 domains from the PDB, have all failed (data not shown). On the other hand, the strong twinning component in the crystals is further likely to make structure solution and refinement complicated, 
bioRxiv preprint doi: https://doi.org/10.1101/051425; this version posted May 3, 2016. The copyright holder for this preprint (which was not certified by peer review) is the author/funder. All rights reserved. No reuse allowed without permission.

even at sub-atomic resolution. Given all the caveats above, once the structure can be solved, it will provide a major increase in the understanding of Shank structure and interactions.

\section{Acknowledgements}

This work has been supported by the Sigrid Jusélius Foundation (Finland), the Emil Aaltonen Foundation (Finland), and the Academy of Finland. The use of computing facilities at the Hamburg Centre for Bioinformatics, as well as beamtime and support at the ESRF, are gratefully acknowledged. We specifically wish to thank Juha Kallio for data collection at ESRF.

\section{References}

Boeckers, T. M., Bockmann, J., Kreutz, M. R. \& Gundelfinger, E. D. (2002). J Neurochem 81, 903-910.

Boeckers, T. M., Kreutz, M. R., Winter, C., Zuschratter, W., Smalla, K. H., Sanmarti-Vila, L., Wex, H., Langnaese, K., Bockmann, J., Garner, C. C. \& Gundelfinger, E. D. (1999). J Neurosci 19, 6506-6518.

Durand, C. M., Betancur, C., Boeckers, T. M., Bockmann, J., Chaste, P., Fauchereau, F., Nygren, G., Rastam, M., Gillberg, I. C., Anckarsater, H., Sponheim, E., Goubran-Botros, H., Delorme, R., Chabane, N., Mouren-Simeoni, M. C., de Mas, P., Bieth, E., Roge, B., Heron, D., Burglen, L., Gillberg, C., Leboyer, M. \& Bourgeron, T. (2007). Nat Genet 39, 25-27.

Grabrucker, S., Proepper, C., Mangus, K., Eckert, M., Chhabra, R., Schmeisser, M. J., Boeckers, T. M. \& Grabrucker, A. M. (2014). Exp Neurol 253, 126-137.

Grubb, D. R., Iliades, P., Cooley, N., Yu, Y. L., Luo, J., Filtz, T. M. \& Woodcock, E. A. (2011). FASEB J 25, 1040-1047.

Hammarström, M., Woestenenk, E. A., Hellgren, N., Hard, T. \& Berglund, H. (2006). J Struct Funct Genomics 7, 1-14.

Han, K., Holder, J. L. J., Schaaf, C. P., Lu, H., Chen, H., Kang, H., Tang, J., Wu, Z., Hao, S., Cheung, S. W., Yu, P., Sun, H., Breman, A. M., Patel, A., Lu, H. C. \& Zoghbi, H. Y. (2013). Nature 503, 72-77.

Kabsch, W. (2010). Acta Cryst D 66, 125-132.

Kabsch, W. (1988). J. Appl. Cryst. 21, 67-72.

Naisbitt, S., Kim, E., Tu, J. C., Xiao, B., Sala, C., Valtschanoff, J., Weinberg, R. J., Worley, P. F. \& Sheng, M. (1999). Neuron 23, 569-582.

Sheng, M. \& Kim, E. (2000). J Cell Sci 113, 1851-1856.

Studier, F.W. (2005). Protein Expr Purif 41, 207-234.

Tu, J. C., Xiao, B., Naisbitt, S., Yuan, J. P., Petralia, R. S., Brakeman, P., Doan, A., Aakalu, V. K., Lanahan, A. A., Sheng, M. \& Worley, P. F. (1999). Neuron 23, 583-592.

van den Berg, S., Lofdahl, P. A., Hard, T. \& Berglund, H. (2006). J Biotechnol 121, 291-298.

Wilson, H. L., Crolla, J. A., Walker, D., Artifoni, L., Dallapiccola, B., Takano, T., Vasudevan, P., Huang, S., Maloney, V., Yobb, T., Quarrell, O. \& McDermid, H. E. (2008). Eur J Hum Genet 16, 1301-1310.

Zitzer, H., Honck, H. H., Bachner, D., Richter, D. \& Kreienkamp, H. J. (1999). J Biol Chem 274, 32997-33001.

Zwart, P. H., Grosse-Kunstleve, R. W. \& Adams, P. D. (2005). CCP4 Newsletter 42, 10. 